\title{
Anrechnung ausländischer Steuern
}

Ausländische Steuern sind wie Werbungskosten zu berücksichtigen, wenn sie nach § 34c Abs. 2 und 3 EStG abzuziehen sind.

Bei unbeschränkt Steuerpflichtigen, die mit ausländischen Einkünften in dem Staat, aus dem die Einkünfte stammen, zu einer der deutschen Einkommensteuer entsprechenden Steuer herangezogen werden, ist die festgesetzte und gezahlte und um einen entstandenen Ermäßigungsanspruch gekürzte ausländische Steuer auf die deutsche Einkommensteuer anzurechnen, die auf die Einkünfte aus diesem Staat entfällt; das gilt nicht für Einkünfte aus Kapitalvermögen, auf die $\S 32$ d Abs. 1 und 3 bis 6 anzuwenden ist ( $\$ 34 \mathrm{c} \mathrm{Abs.} 1$ EStG).

Nach $\S 32$ d Abs. 1 EStG beträgt die ESt für Einkünfte aus Kapitalvermögen, die nicht unter $\S 20$ Abs. 8 fallen (d. h. Einkünften aus Land- und Forstwirtschaft, aus Gewerbebetrieb, aus selbstständiger Arbeit oder aus Vermietung und Verpachtung), $25 \%$. Diese Steuer vermindert sich um die anrechenbaren ausländischen Steuern. Regelungen zu den anrechenbaren ausländischen Steuern finden sich in § 34c EStG und in den Doppelbesteuerungsabkommen (s. Anhang).

Die nach $\S 34 c$ Abs. 1 und Abs. 6 EStG auf die deutsche ESt anzurechnende oder nach $\S 34 \mathrm{c}$ Abs. 2, 3 und 6 EStG bei der Ermittlung der Einkünfte abzuziehende ausländische Steuer ist auf der Grundlage der von der Europäischen Zentralbank täglich veröffentlichten Euro-Referenzkurse umzurechnen. Zur Vereinfachung ist die Umrechnung dieser Währungen auch nach den Umsatzsteuer-Umrechnungskursen zulässig, die monatlich im Bundessteuerblatt Teil 1 veröffentlicht werden. 